\title{
Aplicação de Ferramentas CAE/CAD e Inventor como demonstração de forças nos planos horizontal e inclinado para a primeira série do ensino médio
}

\author{
Heleyne Karen Lima Gil ${ }^{1}$, Dr. Igor Tavares Padilha² \\ ${ }^{1}$ Instituto Federal do Amazonas (IFAM) \\ 1,2 Universidade Federal do Amazonas (UFAM)
}

Palavras-Chave: Ferramentas CAE/CAD e Inventor, Ensino, Aprendizado, Demonstração, Forças.

\section{Introdução}

O conceito abordado para elaboração do projeto é o estudo dinâmico de forças com destaque no projeto para análise em um plano horizontal e inclinado conteúdo esse de difícil visualização por parte da maioria dos discentes em relação ao fenômeno ocorrido.

Ferramentas CAE/CAD (do Inglês, Engenharia Auxiliada por computador e Desenho assistido por Computador) despertarão a curiosidade dos alunos, integrando-os à tecnologia e dando sentido ao que estudam em sala de aula, já que apresentam uma demonstração prática de como o conteúdo de aplicação de forças poderá ser útil para a vida de todos os discentes, não só os que pretendem ter uma carreira focada na área de exatas ou particularmente na área de Engenharia.

\section{Metodologia e Material}

Os softwares que serão utilizados no Projeto serão o Autodesk AutoCAD e o Autodesk Inventor 3D 2016, ambos em versão estudantil.

A principal abordagem metodológica será as aulas teóricas do conteúdo, seguidas de demonstração através das ferramentas utilizadas, visando diminuir a dificuldade que os alunos possuem em visualizar os fenômenos estudados.

A abordagem do conteúdo sobre o estudo de forças será através de análise e cálculos, inicialmente sobre plano horizontal e inclinado, além da demonstração de como funciona a ferramenta e sua importância no cotidiano da Engenharia e como se pode também demonstrar 0 uso didático para a visualização desse plano em Física I.

Como Embasamento Teórico para o Projeto, tem-se o conceito central da Teoria de Vygotsky, que é o de atividade, sendo a unidade funcional de arquitetura funcional da consciência. Um sistema de transformação do meio (externo e interno da consciência) com ajuda de instrumentos (orientados externamente devem necessariamente levar a mudanças nos objetos e signos (orientados internamente; dirigidos para o controle do próprio individuo).

\section{Resultados Esperados}

O projeto proposto está em fase de aplicação. Como resultados, espera-se que a contribuição no ensino seja de: maior compreensão e visualização do conteúdo para toda a turma; ensinar um grupo de alunos selecionados como trabalhar essa ferramenta. Como parte do produto final, proponho a análise e estudos de casos de aplicação de forças a serem elaboradas pelos próprios alunos selecionados, comparando a método obtido ao método convencional; além de apresentação de resultados através de relatos de experiência, comparações com o processo didático de ensino regular e artigo.

\section{Agradecimentos}

Ao Programa de Mestrado MNPEF - Polo 04, pela oportunidade de trabalhar metodologias que possam colaborar com a melhoria no Ensino de Física; à Capes, pelo incentivo à pesquisa; e à FAPEAM, pela bolsa de estudo. 


\section{Referências}

AMARAL, R. D. C.; FILHO, A. C. P. A Evolução do CAD e sua Aplicação em Projetos de Engenharia. Rio de Janeiro: UFRJ, Escola Politécnica, Departamento de Engenharia Mecânica, 2010.

RAMALHO JUNIOR, F.; FERRARO, N.; TOLEDO, P. A. Os Fundamentos da Física I. São Paulo: 2009.

BRASIL. Secretaria de Educação Média e Tecnológica. Parâmetros Curriculares Nacionais + Ensino Médio: Orientações Educacionais Complementares aos Parâmetros Curriculares Nacionais - ciências da natureza, matemática e suas tecnologias. Brasília: MEC; SEMTEC, 2002. 